\title{
CONE)-(oES
}

CIÊNCIA E TECNOLOGIA

\section{RELATO DE UMA EXPERIÊNCIA DIDÁTICA: MOSTRA DE FÍSICA}

\author{
Nadia Ferreira de Andrade Esmeraldo, Renato TeIXeira Moreira \\ Instituto Federal de Educação, Ciência e Tecnologia do Ceará - IFCE \\ <nadiafisica@gmail.com>, <renato.teixeira@ifce.edu.br> \\ DOI: $10.21439 /$ conexoes.v15i0.2110
}

\begin{abstract}
Resumo. Neste trabalho, relata-se a experiência de uma Mostra de Física ocorrida em uma instituição de Ensino de nível técnico e superior. Essa atividade pedagógica com alto potencial didático envolveu diretamente os alunos matriculados nas disciplinas de Física dos cursos de Engenharia. O objetivo deste relato, além de descrever o evento, é identificar os seus benefícios para o ensino de Ciências, mais especificamente para a disciplina de Física. No citado evento, os alunos se organizaram previamente em equipes e apresentaram diferentes experimentos envolvendo conteúdos teóricos dos mais diversos assuntos ministrados em sala de aula. Além do espaço de exposição de experimentos, foi criado um ambiente de observação astronômica com o uso de telescópios, possibilitando-se a observação do céu noturno e identificação dos planetas visíveis na ocasião. Além dos alunos matriculados nas disciplinas de Física, alunos de uma escola estadual da região foram convidados para participar da mostra e um momento de intensa troca de conhecimentos foi estabelecido. A conclusão deste relato de experiência foi que o aprendizado, quando transpõe as paredes da sala de aula, explora diversas habilidades fundamentais para o processo de crescimento pessoal e cognitivo dos alunos envolvidos diretamente no processo.
\end{abstract}

Palavras-chaves: Ensino de Física. Atividades Experimentais. Mostra de Física.

\section{REPORT OF A TEACHING EXPERIENCE: PHYSICS EXHIBIT}

\begin{abstract}
This paper reports the experience of a Physics Exhibition in a technical and higher education institution. This pedagogical activity with high didactic potential involved students enrolled in Physics in Engineering courses. This report aims to describe the event and identify the benefits of science teaching, more specifically for Physics. Students were previously organized in teams to present different experiments involving theoretical contents of diverse subjects taught in the classroom. Additionally, an astronomical observation environment was created on the event using telescopes, making it possible to observe the night sky and identify the planets visible at the time. Students enrolled in Physics subjects from a state school in the region were invited to participate in the exhibition. As a result, a moment of intense exchange of knowledge was established. This experience concluded that learning beyond the classroom explores several fundamental skills for personal and cognitive growth directly involved in the process.
\end{abstract}

Keywords: Teaching Physics. Experimental Activities. Physics Exhibit.

\section{INTRODUÇÃO}

O ensino de Física se torna uma preocupação para muitos profissionais da área de Educação, pois esta disciplina, muitas vezes, é vista pelos alunos como de difícil compreensão (SILVA; DUARTE, 2018). Muitos estudantes apresentam dificuldades no aprendizado e isso se dá por diferentes fatores. O desconhecimento da linguagem matemática envolvida, o distanciamento entre o que é exposto em sala de aula e contextos do coti- diano, a pouca exploração da interdisciplinaridade, ou ainda, o distanciamento entre professor e aluno são alguns pontos relevantes (FERNANDES, 2016).

Apesar disso, é inegável a importância do estudo da Física e de sua compreensão frente a uma sociedade tecnológica que passa constantemente por processos de rápido desenvolvimento. Características exploradas ao longo do estudo de uma disciplina de Física como raciocínio lógico, crítico e investigativo são aspectos im- 
RELATO DE UMA EXPERIÊNCIA DIDÁTICA: MOSTRA DE FÍSICA

portantes e diferenciais para a formação do sujeito. Em 2012, a Sociedade Brasileira de Física (SBF) lançou o relatório "A Física e o desenvolvimento nacional" em parceria com o Centro de Gestão e Estudos Estratégicos (CGEE) e apoio da Financiadora de Estudos e Projetos (Finep). Este relatório evidencia a importância do estudo, divulgação e investimento nessa área. Um possível entrave ao aprendizado de Física se deve às metodologias de ensino adotadas por boa parte das escolas que se baseiam em modelos de ensino tradicional. Nesse formato, as aulas são expositivas e centradas no professor, pouco valorizando o conhecimento pré-existente dos alunos, ganhando destaque a memorização de fórmulas e a ausência de correlação entre teoria e prática (DUARTE, 2018).

Esse ensino tradicional tem se demonstrado inadequado, tendo em vista a atual dinâmica social na qual os alunos estão inseridos, revelando-se ineficiente para aprimorar o estudante como indivíduo, além de não favorecer o desenvolvimento da sua autonomia intelectual, do seu pensamento crítico e da compreensão das bases científicas e tecnológicas tão importantes numa sociedade permeada de recursos digitais. Ademais dos pontos negativos elencados, o método tradicional de ensino da Física não tem proporcionado relação direta entre teoria e prática, sendo talvez, o principal problema no ensino da disciplina (BRASIL, 1996).

Sendo assim, expõe-se, neste artigo, um relato de experiência referente a uma alternativa de metodologia com potencial para diminuir ou mesmo evitar problemas recorrentes e usuais no ensino de Física. Seu objetivo é a aprendizagem aplicada e o desenvolvimento de experimentos. Tal alternativa trata-se da adoção da Mostra de Física como parte da integrante do planejamento letivo.

No caso aqui relatado, o evento foi destinado às turmas dos primeiros anos dos cursos de Engenharia de uma instituição de Ensino superior e técnico e aberto à participação da comunidade externa, com a presença de alunos do ensino médio de uma escola pública convidada. A mostra, além de explorar o aprendizado exposto em sala de aula, contribui para o desenvolvimento de diferentes habilidades como trabalho em equipe, pensamento investigativo e transposição do conhecimento em diferentes circunstâncias e aplicações.

\section{FUNDAMENTAÇÃO}

O modelo de ensino tradicional é o que se estabelece na maioria das escolas e universidades, sejam públicas ou privadas. Tal ensino se limita, quase exclusivamente, ao ensino dos conteúdos de forma expositiva, sendo, quase sempre, entendido como transferência do saber (FREIRE, 2003). Com a nova estruturação da sociedade moderna, faz-se necessário romper com a estrutura tradicional, descentralizando o papel do professor e proporcionando ao aluno tornar-se agente ativo do processo de ensino e aprendizagem.

O destaque para a importância das atividades práticas na educação desde as idades iniciais possui defensores como Fröbel (2001), Montessori (1965), Montessori (2003), Dewey (1978). As ideias desses autores estão voltadas para a valorização do aprender com a prática, bem como o incentivo da autonomia e curiosidade, além da exploração do meio pelo indivíduo. Essas ideias acompanhadas das experiências prévias de cada um, permitem o desenvolvimento global do indivíduo, dando espaço para o pensar reflexivo e transformador. No entanto, do ponto de vista da realidade brasileira e; mais especificamente, da realidade cearense, o método de ensino tradicional é não só o mais utilizado como também o mais desejado pela sociedade (LEÃO, 1999).

A importância de lançar mão de novas metodologias de ensino se faz necessária para a formação e construção de um sujeito pleno e integral. O papel do professor é fundamental, pois este deve tentar desafiar os alunos com o ensino do conteúdo, para que esses possam se perceber na prática e pela própria prática como sujeitos capazes de saber. Nesse contexto, a função do professor não é apenas o de ensinar conteúdos, mas tratar temáticas de forma integradora entre o objeto de ensino e a aprendizagem do aluno. De maneira que o professor auxilia o aluno a se reconhecer como arquiteto de sua própria prática cognoscitiva. (FREIRE, 2003). Nesse cenário, destacam-se as estratégias de ensino que valorizam o aprender fazendo e que transformam o aluno em agente ativo do processo de desenvolvimento intelectual. Essas abordagens incitam a criatividade e dão ênfase a um comportamento investigativo e reflexivo, com foco no sujeito e exploram a observação, a expressão, a comunicação e a verificação das hipóteses levantadas (BATISTA; FUSINATO; BLINI, 2009).

De acordo com os parâmetros curriculares nacionais (BRASIL, 2002), ao longo de todo o processo de aprendizagem do aluno, a experimentação deve estar presente. A experimentação, por sua vez, está intimamente relacionada à observação, visto que é por meio do desenvolvimento de experimentos que se controla, provoca e prevê diferentes manifestações fenomenológicas.

Para que a experimentação possa ser explorada de forma eficiente, é necessário que as atividades assegurem um espaço de desenvolvimento, construção de ideias e pensamento reflexivo. Quando se solicita aos estudantes uma participação mais ativa por meio da 
elaboração ou execução de experimentos, a autonomia dos estudantes torna-se ainda mais significativa. Deste modo, a proposta de ensinar Física por meio de atividades experimentais torna o ensino mais bem contextualizado, despertando no estudante autonomia, curiosidade e participação (SILVA; DUARTE, 2018). Além da criação e execução, o momento de discussão dos resultados e exposição dos problemas e erros envolvidos é de grande importância, pois a troca de conhecimento e de experiências se manifesta de forma ampla e eficaz.

No caso do ensino de Física, é possível identificar extensa bibliografia que aborda o uso de atividades práticas, explorando diferentes estratégias. Aspectos como a simples contestação de leis físicas ou a verificação de fenômenos físicos em diferentes perspectivas podem ser encontrados nas mais diversas áreas. Araújo e Abib (2003) analisam mais de 100 publicações investigando a experimentação como estratégia no ensino de Física. O resultado da pesquisa é um indicativo de que a experimentação é um tema de grande interesse com uma grande variedade de enfoques e finalidades para o ensino (ARAÚJO; ABIB, 2003).

A proposta de ensino prático, seja através da pedagogia de projetos, ou por exposição de aulas experimentais, segue uma abordagem didática que desloca o professor do centro do processo e dá lugar ao aluno, de modo que este assume o papel de protagonista do seu processo de aprendizagem. Quando esta metodologia se estende além da sala de aula, é possível ainda que se explore a colaboração dos alunos entre si, permitindo que estes sejam colaboradores no aprendizado de outros indivíduos, sejam colegas de turma, ou não.

A aula prática é um recurso facilitador no processo de ensino-aprendizagem, pois com ela se estabelece a teoria aliada à prática e isso possibilita o despertar por meio da curiosidade (GOMES; PINTO; FILHO, 2017). Esta abordagem possibilita que o aluno desenvolva habilidades e competências específicas. Além disso, no ensino de Física, as aulas práticas estimulam a curiosidade e o interesse discente, permitindo que se envolvam em investigações científicas, ampliem a capacidade de resolver problemas, de compreender conceitos básicos, além de desenvolver habilidades. As atividades experimentais desenvolvidas por meio de aulas práticas, quando bem planejadas, são recursos importantíssimos e devem estar aliadas à conduta e abordagem do professor em sala de aula.

Tendo em vista a importância de se atentar para o aprendizado do indivíduo à luz de teorias pedagógicas já bem estabelecidas, faz-se necessária a utilização de ferramentas que permitam estabelecer e explorar as potencialidades do indivíduo, permitindo-lhe agregar va- lor ao conteúdo exposto em sala de aula, a partir do seu conhecimento pré-determinado (JOYE, 2013). Por meio da utilização de atividades práticas idealizadas e desenvolvidas pelos próprios alunos, é possível explorar não só os conhecimentos adquiridos nas aulas expositivas, mas também habilidades, capacidades e competências.

Para que atividades experimentais sejam inseridas dentro do contexto da sala de aula, é necessário que o professor tenha autonomia. Contreras (2012) afirma que a viabilidade de uma prática docente transformadora cultural e social passa por uma autonomia profissional. Em geral, considera-se o grau de autonomia presente nas instituições de ensino como algo relativo por resultar de documentos oficiais construídos isoladamente dos profissionais e da realidade educacional. Mesmo diante de diferentes contextos em que se encontram os professores, vale destacar a importância do apoio do corpo docente e da gestão de ensino para que atividades alternativas que explorem o lúdico e o prático possam ser inseridas no contexto da sala de aula.

Nesse contexto em que se explora o aprender fazendo, verifica-se muitos dos aspectos descritos por Tardif (2011) sobre os diferentes saberes que podem ser explorados a partir desta abordagem. Além dos saberes produzidos pelas ciências da educação e dos saberes pedagógicos, temos os saberes disciplinares, os saberes curriculares e os saberes experienciais ou práticos. Apesar das dificuldades e eventualidades encontradas pelos alunos e mesmo pelos professores, o desenvolvimento de atividades práticas estabelece uma aprendizagem significativa, de modo que explora consideravelmente os saberes experienciais.

\section{METODOLOGIA}

Sob a perspectiva metodológica, este trabalho é um relato de experiência. Dentre os vários métodos científicos usados para elaboração de pesquisas descritivas, o relato de experiência é um deles. Relata-se, sobretudo, para narrar uma experiência: didática, profissional, aplicação de uma técnica, realização de uma atividade, um caso clínico, entre outros.

Diante de algumas dificuldades apresentadas pelos alunos nas disciplinas de Física, buscou-se estratégias que auxiliassem o processo de ensino e aprendizagem. Em meio a muitas reflexões e algumas mudanças de conduta, foi criado um evento que se configurou com uma "Mostra de Física" que, além de motivar os alunos por meio da melhoria de suas notas, estimulou a criatividade e o senso crítico dos estudantes. Tal evento fez com que os alunos pesquisassem, idealizassem e construíssem diferentes experimentos envolvendo assuntos 
expostos ao longo das aulas expositivas.

Nessa atividade, os alunos se dividiram em equipes e apresentaram algumas experiências envolvendo conteúdos de Física estudados em sala de aula. As atividades realizadas pelos alunos e apresentadas na Mostra foram desde trabalhos de natureza didática, como a construção de um pêndulo de Newton, até trabalhos com potencial para aplicação em futura profissão, como a montagem de um circuito temporizador. $\mathrm{O}$ evento foi aberto para a comunidade externa e alunos do Ensino Médio de uma escola estadual foram convidados a participar.

Além dos experimentos realizados pelos alunos, foram montados dois telescópios no local do evento, acompanhados de monitores que acompanharam os participantes durante uma observação astronômica. Nesta oportunidade, foram observados planetas visíveis, como Saturno, além da visualização da Lua. Além disso, foi criado um espaço onde estavam disponíveis óculos de realidade virtual com os quais os alunos tinham a oportunidade de passear pela Estação Espacial Internacional (ISS) e experimentar a microgravidade.

Participaram da Mostra de Física os alunos matriculados nas disciplinas de Física e; de acordo com o cronograma seguido nas disciplinas, foram realizados experimentos envolvendo conceitos de Mecânica, Eletricidade e Magnetismo. Além da realização dos experimentos pelas equipes, os alunos tiveram todo o cuidado de confeccionar banners com toda a explicação teórica do assunto escolhido.

Os discentes se distribuíram ao longo de um amplo espaço e cada equipe montou seu experimento em um lugar previamente reservado. Ao longo do evento, os convidados e os participantes interagiram com as equipes que apresentavam seus trabalhos e, enquanto isso, uma banca avaliadora passava por cada equipe e analisava as apresentações. A banca era formada por quatro (04) professores convidados, além do professor da disciplina. Cada professor recebia uma prancheta com alguns pontos a serem avaliados, entre os quais: relação do trabalho com a Física, criatividade, capricho na execução e participação de todos os membros da equipe. As notas da banca avaliadora foram computadas e uma média foi obtida. A Mostra de Física foi utilizada como ferramenta avaliativa e a nota obtida pela equipe substituiu a menor nota dos alunos ao longo da disciplina. Esta atividade realizada pelos alunos, além de motivar o aprendizado de forma lúdica por meio do desenvolvimento de experimentos, ainda substituiu a menor nota dos alunos que apresentaram trabalhos no evento.

\section{RESULTADOS E DISCUSSÃO DA EXPERI- ÊNCIA}

Com a criação da Mostra de Física, os alunos mostraram grande interesse na realização e participação do evento e, ao longo do semestre, buscaram se aprofundar nos conteúdos, para explorar, por meio dos experimentos, os conceitos físicos aprendidos nas aulas expositivas. Foi possível observar que, após essa ação, ocorreu um aumento significativo no interesse dos alunos pela disciplina de Física, além de demonstrações de maior interesse pelas aulas e maior busca por compreender os fenômenos físicos.

Alguns alunos descreveram experimentos envolvendo os conceitos de Cinemática, explorando a descrição dos movimentos, diferenciando o retilíneo uniforme (MRU) do retilíneo uniformemente variado (MRUV), por meio do movimento de uma esfera em um fluido viscoso (Figura 1). As forças de atuação, neste caso, são o peso para baixo, o empuxo para cima e uma terceira força de resistência ao movimento da partícula no fluido conhecida como força de arrasto. As três forças se compensam, de modo que a partícula atinge a velocidade terminal ao se deslocar pelo fluido, sendo essa velocidade constante. Com este experimento, foi possível realizar um estudo do MRU.

Outro tipo de movimento explorado foi o lançamento oblíquo, descrito e reproduzido por meio do lançamento de um foguete construído pelos alunos com garrafas descartáveis de refrigerante (Figura 2).

Os alunos construíram tanto a base de lançamento como os foguetes, que foram lançados a partir de um sistema de propulsão que funciona com vinagre e bicarbonato de sódio. A reação libera gás carbônico de modo que a pressão no interior da garrafa aumenta e como consequência, ela é violentamente repelida e lançada longe.

Ao longo do eixo y é descrito um MRUV devido à aceleração da gravidade. Nesse eixo é possível determinar a altura máxima que o objeto alcança. Ao longo do eixo x é descrito um MRU e é possível determinar o alcance horizontal do objeto. Com este experimento, foi possível identificar diretamente as variáveis descritas nas equações algébricas da teoria com a descrição do movimento realizado a partir do lançamento do foguete.

Explorando o assunto de Dinâmica, abordado nas aulas expositivas, uma equipe desenvolveu um experimento envolvendo a construção de um sistema de polias (Figura 3). As polias, quando associadas da forma correta, reduzem o esforço necessário para levantar determinado objeto. Os alunos utilizaram como suporte uma trave de futebol da própria instituição, na qual foram 


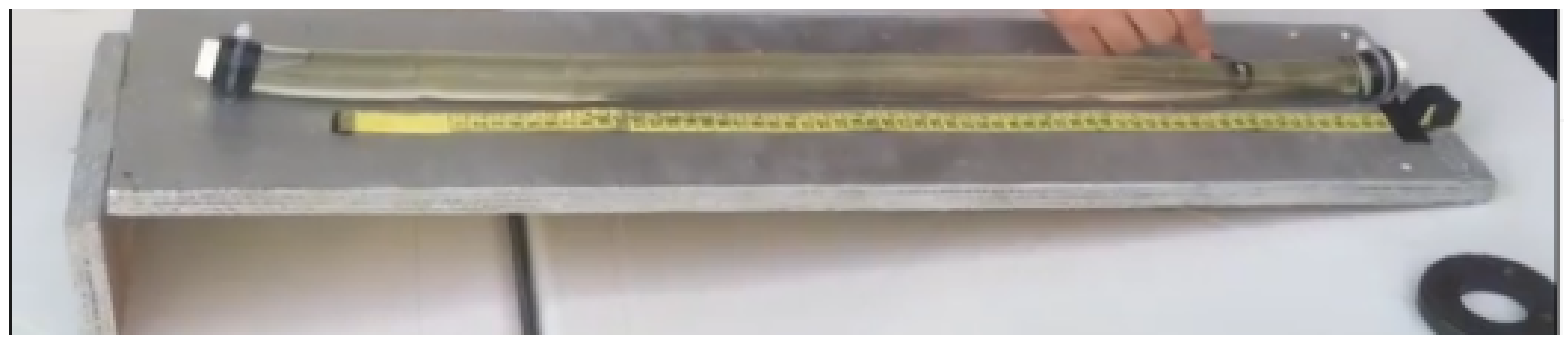

Figura 2: Experimentos envolvendo lançamento oblíquo.

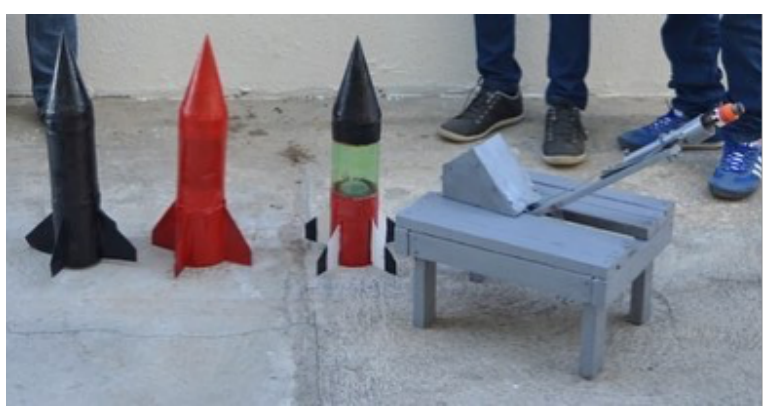

anexadas polias fixas e móveis de diferentes tamanhos. As polias utilizam correias ou correntes para transmitir o movimento. Para o experimento realizado, os alunos utilizaram uma corda de seda e diferentes objetos com massas distintas foram amarrados à corda vinculada às polias. Dentre os objetos suspensos, os alunos trouxeram um saco de areia de $20 \mathrm{~kg}$ e mostraram o efeito de suspendê-lo com o auxílio do sistema de polias e sem o auxílio do sistema de polias, mostrando que o sistema de polias facilita consideravelmente o processo.

Outro experimento envolvendo Dinâmica foi o estudo do equilíbrio de corpos extensos (Figura 4). Um corpo extenso é aquele que não pode ser considerado uma partícula e estes corpos possuem um ponto especial, conhecido como centro de gravidade. Se o corpo estiver sujeito a um campo gravitacional homogêneo, o centro de massa coincide com o centro de gravidade. O centro de massa é um ponto que se comporta como se toda a massa do corpo estivesse concentrada nele. Neste experimento, os alunos equilibraram diferentes objetos, como latas vazias e com água, garrafas com volumes diferentes de água e talheres suspensos por palitos de fósforo. Eles criaram um suporte com um cano PVC com diferentes furos onde suspenderam garrafas com diferentes volumes. A garrafa de volume maior ficou em equilíbrio quando suspensa pelo furo superior enquanto a garrafa de volume menor pelo furo inferior identificando que a distribuição de massa do sistema in-
Figura 3: Experimento envolvendo a construção de um sistema de polias.

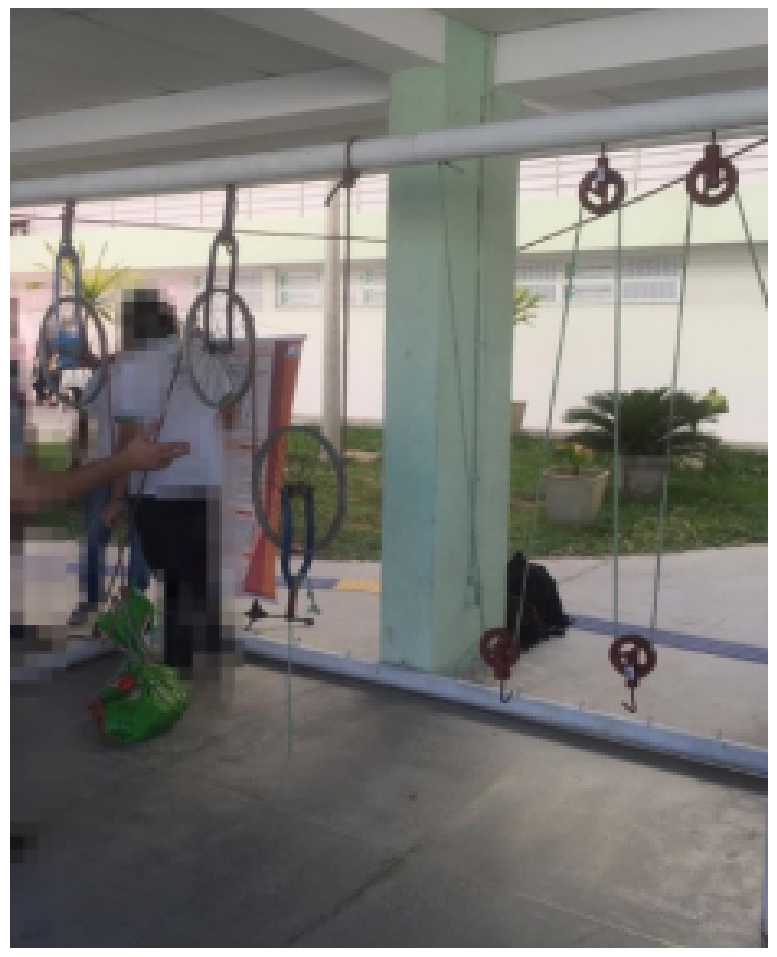

terfere na posição do ponto do centro de massa. Com este experimento, os alunos exploraram os conceitos de equilíbrio e centro de massa e ainda identificaram na prática que o centro de massa de um objeto não precisa estar necessariamente no interior do objeto.

Uma equipe decidiu realizar um experimento que descreveu a lei de conservação da energia mecânica a partir da transformação de energia potencial em energia cinética (Figura 5). Neste experimento, os alunos construíram um carrinho de ratoeira utilizando materiais de baixo custo.

Nesse sistema, a mola que aciona a ratoeira armazena energia potencial que depois se transforma em energia cinética quando o carrinho ratoeira se desarma. 


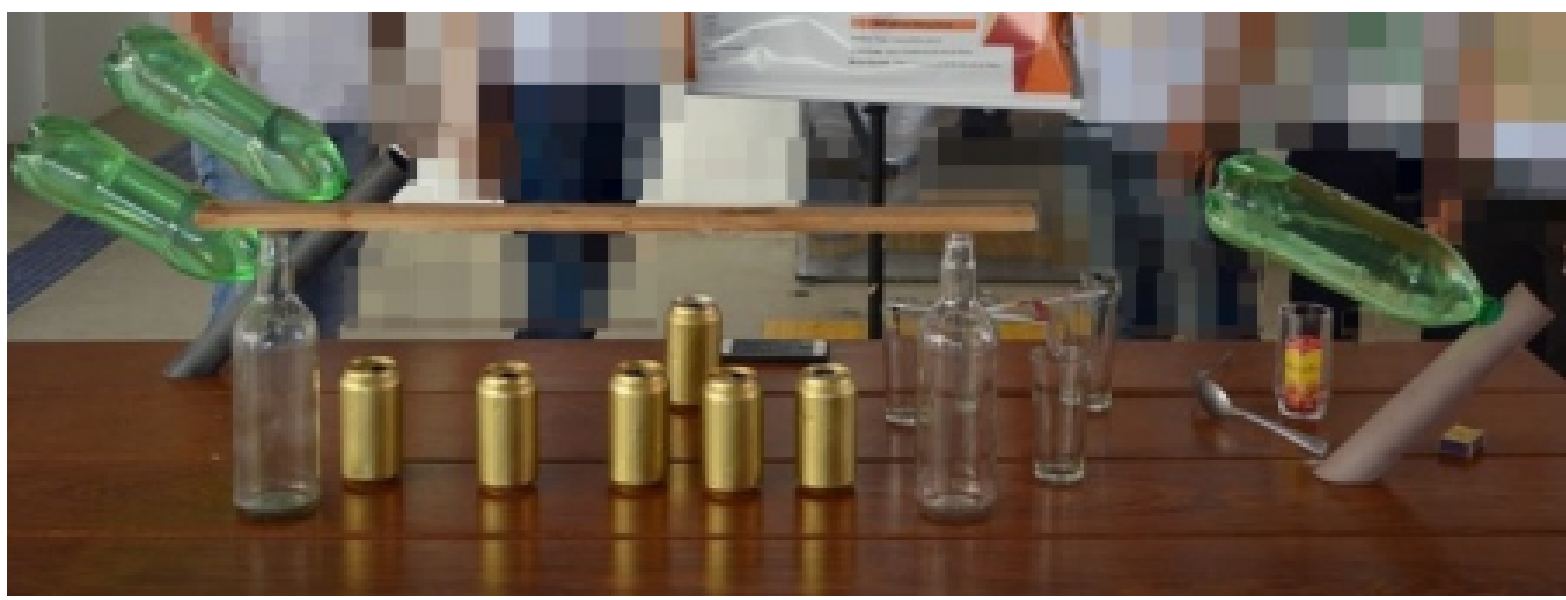

Figura 5: Experimento de Conservação de Energia.

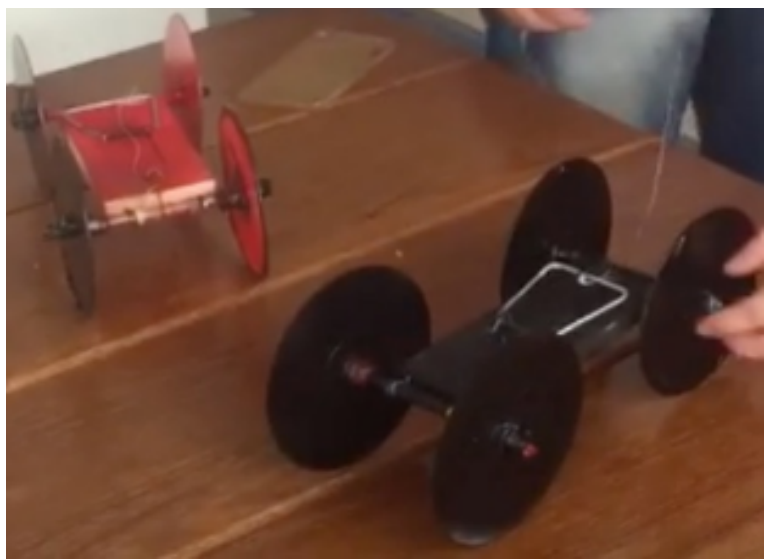

Quando a ratoeira se desarma, o carrinho passa a ter energia na forma de energia cinética e adquire movimento, deslocando-se sobre a superfície. Ainda explorando as leis de conservação na Física, alguns alunos construíram uma estrutura conhecida como pêndulo de Newton a partir de um conjunto de bolas de bilhar (Figura 6 .

Os alunos idealizaram e confeccionaram a estrutura de madeira e realizaram as conexões adequadas das bolas de bilhar à estrutura a partir de fios de nylon. Esta estrutura permite a demonstração de conceitos básicos do estudo de Mecânica como a conservação do momento linear e da energia mecânica de um sistema. Ainda explorando os conceitos de conservação e transformação de energia, esta mesma equipe montou um outro experimento sobre a transformação de energia potencial gravitacional em energia cinética. Para esta experiência, montaram um pêndulo confeccionado a partir de
Figura 6: Experimento sobre Pêndulo de Newton.

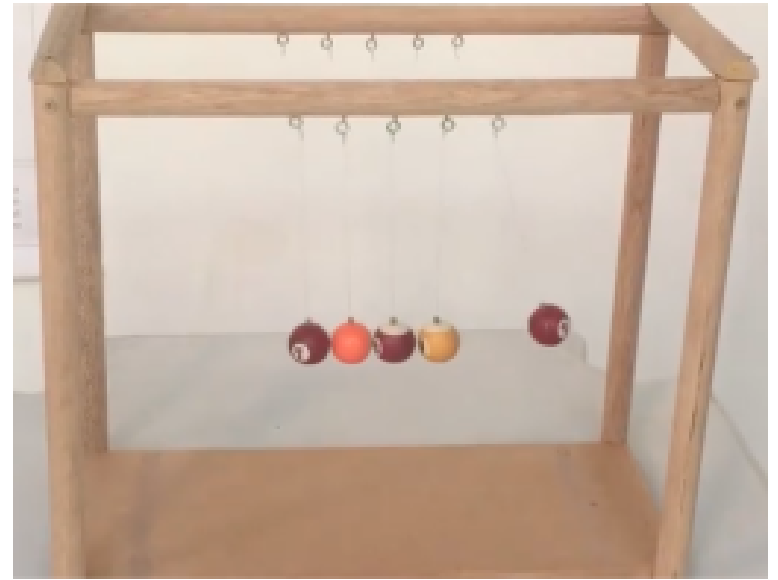

uma bola de cimento bem pesada presa a uma corda (Figura 77. Os alunos prenderam esse pêndulo à uma trave de futebol da própria instituição. Muitos participantes se divertiram e interagiram com este experimento, uma vez que o participante devia permanecer em uma posição fixa e aproximar a bola de cimento na altura de sua face e imediatamente soltá-la para que esta iniciasse seu movimento. A sensação é de que a bola pesada de cimento, no retorno, atinja a face de quem a lançou, no entanto, a bola só tem energia suficiente para retornar ao ponto inicial de lançamento, bem próximo à face, mas não atingindo a face. Muitos alunos se divertiram com a sensação do perigo de ser atingido por um objeto tão pesado.

Outra equipe desenvolveu um experimento que envolve a transformação de energia mecânica em energia elétrica. Esta energia foi suficiente para acender um led (Figura 8). Neste experimento, uma garrafa é suspensa 
RELATO DE UMA EXPERIÊNCIA DIDÁTICA: MOSTRA DE FÍSICA

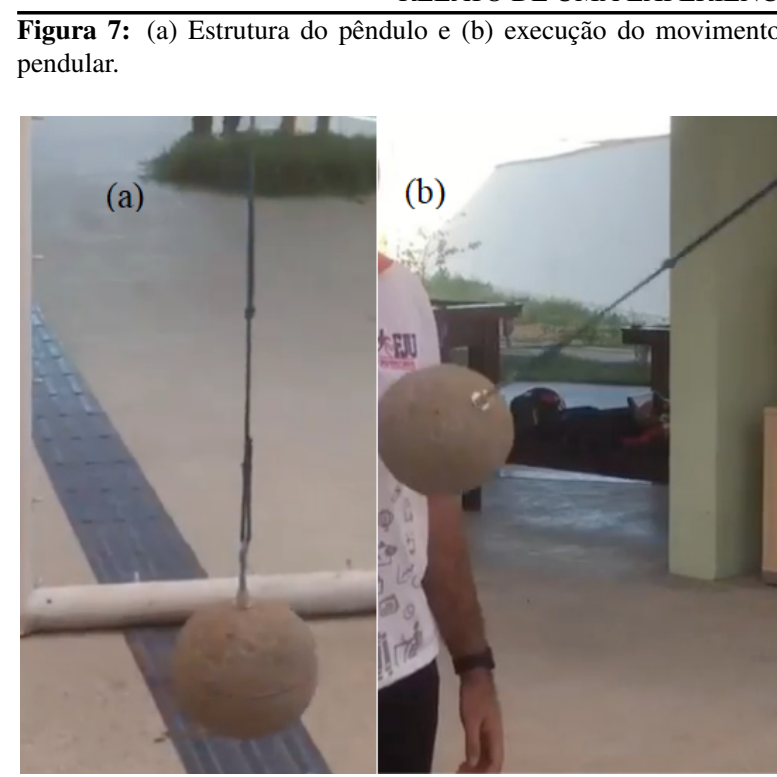

e, ao ser abandonada, move uma manivela que, por sua vez, está ligada a um motor que ao girar cria uma corrente elétrica suficiente para acender o led.

Figura 8: (a) Funcionamento do experimento com o led aceso e (b) estrutura confeccionada.

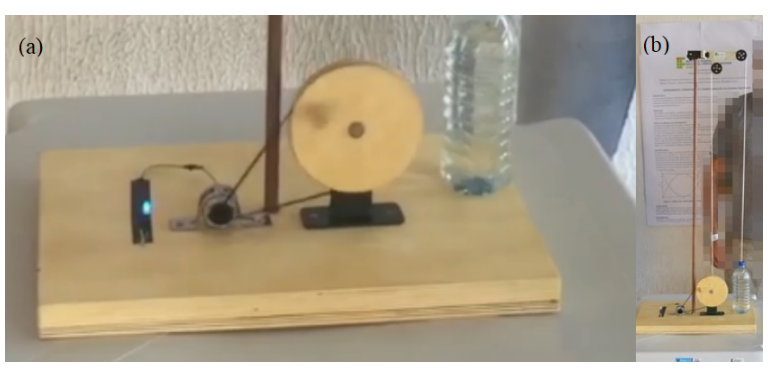

Determinada equipe explorou os conceitos de eletricidade e magnetismo por meio de experimentos envolvendo a montagem de um motor elétrico homopolar, que consiste em um motor simples que explora o funcionamento dos motores elétricos e a construção de uma bobina de Tesla, capaz de acender uma lâmpada mesmo à determinada distância (Figura 9). Para a construção do motor homopolar (Figura 9 (a)) foi necessário um fio de cobre, uma pilha e três ímãs de neodímio. O fio de cobre foi moldado em forma de espiral, possuindo em uma extremidade uma ponta em contato com o polo positivo da pilha e na outra extremidade um anel envolvendo os ímãs de neodímio em contato com o polo negativo da pilha. Quando o fio de cobre conecta o polo positivo ao polo negativo da pilha, cria-se uma corrente elétrica, e o campo magnético criado pelo ímã interage com os elétrons, gerando o movimento observado do fio de cobre (Figura 9 (c))

Para a construção da bobina de Tesla (Figura 9(b)), os alunos confeccionaram uma caixa de MDF e dentro montaram um circuito formado por um transistor, um resistor e uma bateria de $9 \mathrm{~V}$ conectados a um interruptor. Pela caixa de madeira, os alunos atravessaram um cano de PVC envolvido por um fio esmaltado bem fino. Foram realizadas diversas voltas ao longo de todo o comprimento do cano até cobrir perfeitamente o comprimento do cano, obtendo uma bobina secundária. Com outro fio de cobre esmaltado mais grosso, os alunos confeccionaram uma espiral de três voltas, formando uma bobina primária mantida no interior da caixa. Esta bobina primária envolveu a bobina secundária, mantendo contato direto entre elas. A bobina primária, formada pelo fio enrolado grosso, conecta-se ao circuito alimentado pela bateria de 9V. Quando se coloca energia em um fio enrolado, cria-se um eletroímã, portanto, a bobina primária funciona como um ímã. $\mathrm{O}$ experimento consiste em aproximar uma lâmpada fluorescente comum. Na aproximação, a lâmpada se acende mesmo sem ter nenhum fio de ligação à ela e mesmo estando a certa distância do cano de PVC. O que acontece no experimento é que a energia transferida da bobina primária para a bobina secundária é amplificada consideravelmente e isso faz com que se tenha um campo elétrico forte, e; consequentemente, uma alta tensão. $\mathrm{O}$ alto campo elétrico gerado faz com que os elétrons existentes dentro da lâmpada fluorescente se choquem com uma camada de fósforo existente no interior da lâmpada, emitindo luz. Este processo faz com que a lâmpada se acenda momentaneamente quando aproximada à bobina de Tesla.

Outra equipe participante abordou conceitos de circuitos elétricos por meio da construção de um labirinto elétrico e da montagem de uma combinação de associações em série e em paralelo de um sistema de lâmpadas. O labirinto elétrico (Figura 10 (a)) consiste em um caminho moldado por um arame em que se pretende percorrê-lo utilizando uma argola metálica (Figura 10 (c)). A dinâmica criada consistia em não encostar a argola no caminho percorrido, pois ao encostar, um som era emitido por um alto-falante. Os alunos da equipe criaram uma dinâmica com os alunos participantes e distribuíram chocolates a quem conseguisse alcançar o objetivo. O labirinto elétrico (Figura 10 (a)) consiste em um circuito fechado formado por duas pilhas conectadas uma à outra em que uma extremidade das pilhas se liga a um interruptor e a outra extremidade da pilha se liga a um alto-falante. Um fio de arame é utilizado para formar o caminho, este deve ser encurvado ao longo do seu comprimento para dificultar a dinâmica. Uma ex- 


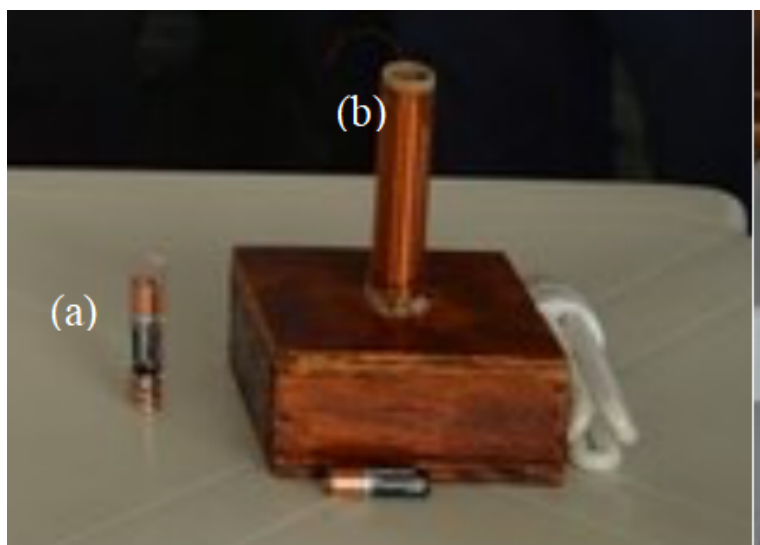

tremidade desse arame deve estar presa à madeira e a outra extremidade conectada ao polo positivo do altofalante e a argola metálica se liga a um fio, o qual, por sua vez, deve estar conectado ao polo positivo da pilha. O objetivo a ser alcançado com essa dinâmica é evitar acionar o alto-falante devido ao fechamento do circuito elétrico.

Figura 10: (a) Labirinto elétrico. (b) Associação mista. (c) Interação dos alunos com o experimento.

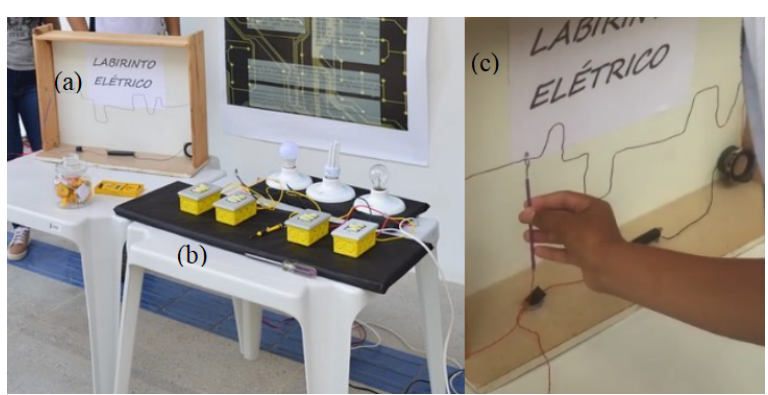

Além do labirinto elétrico, os alunos da equipe montaram um circuito com lâmpadas em série e em paralelo (Figura 10 (b)). Por meio deste experimento, foi possível identificar os conceitos de associação mista, no qual estão envolvidos os tipos de associação tanto em série quanto em paralelo. Na associação em série, a corrente é mantida ao longo do circuito, enquanto a tensão elétrica varia, já na associação em paralelo, tem-se a mesma diferença de potencial com a corrente sendo dividida pelos ramos do circuito. Com a interrupção da passagem da corrente por meio da remoção de uma das lâmpadas do circuito foi possível identificar os tipos de associação existentes no experimento.

Ao todo, foram 10 equipes participando da Mostra de Física. Além dos alunos matriculados nas disciplinas e dos alunos convidados da escola estadual, muitos ser-

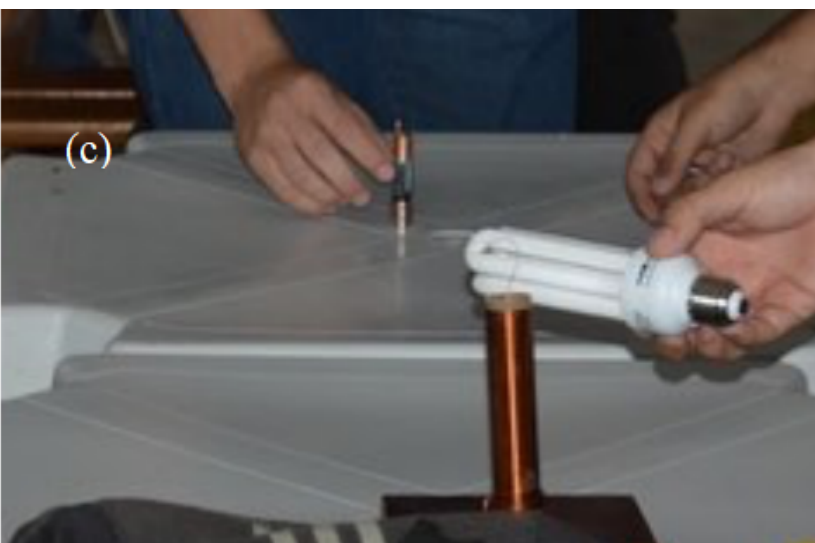

vidores da instituição também participaram do evento, acompanhando as exposições e apresentações dos alunos. Contabilizou-se, em média, a presença de 150 pessoas que passaram pela exposição ao longo do evento. As equipes faziam as apresentações e explicações das experiências tanto para a banca avaliadora como para as outras pessoas que passavam pelas mesas onde as equipes estavam com suas exposições. Por meio do cálculo da média aritmética das notas da banca avaliadora, cada aluno recebeu um conceito que substituiu a menor nota do aluno ao longo do semestre. Esta ação diminuiu consideravelmente o número de reprovações e recuperações dos alunos nas disciplinas.

Além dos experimentos expostos, houve um momento de observação astronômica. Esta ação causou grande euforia nos participantes, tanto nos alunos da instituição como nos convidados da escola e, até mesmo, nos servidores que participaram do momento da observação. Muitos dos presentes nunca tinham tido a oportunidade de ver de perto um telescópio, muito menos tocar em um e ter a oportunidade de visualizar o céu noturno. Ao final da observação astronômica, um aluno agradeceu pela oportunidade e disse que naquele dia tinha sido proporcionado a ele a realização de um sonho, que era a possibilidade de não só ver um telescópio de perto, mas visualizar a Lua e um planeta, coisas vistas, até então, apenas em livros, revistas e internet.

Dois telescópios (Figura 11) foram dispostos em posições diferentes, um apontando para a lua (Figura 11 a) e outro apontando para Saturno (Figura 11 p) que na ocasião estava visível. Duas extensas filas se formaram com o intuito de conseguir visualizar o céu noturno por meio dos telescópios.

Foi possível na observação astronômica visualizar a Lua com suas crateras (Figura 12) e Saturno com seus anéis. 
Figura 11: Telescópios utilizados, um voltado à observação da Lua (a) e outro para Saturno (b).

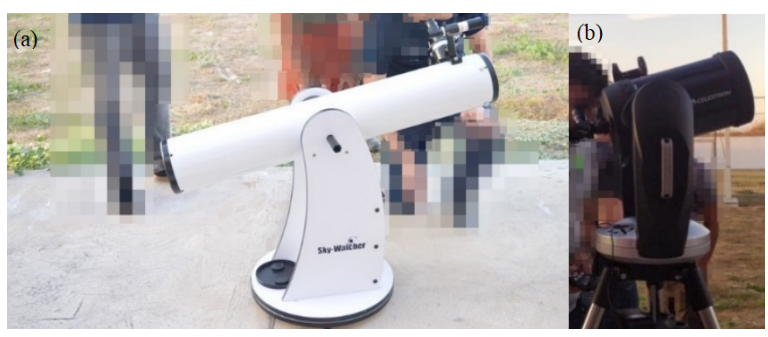

Figura 12: Foto da Lua no momento da observação astronômica realizada.

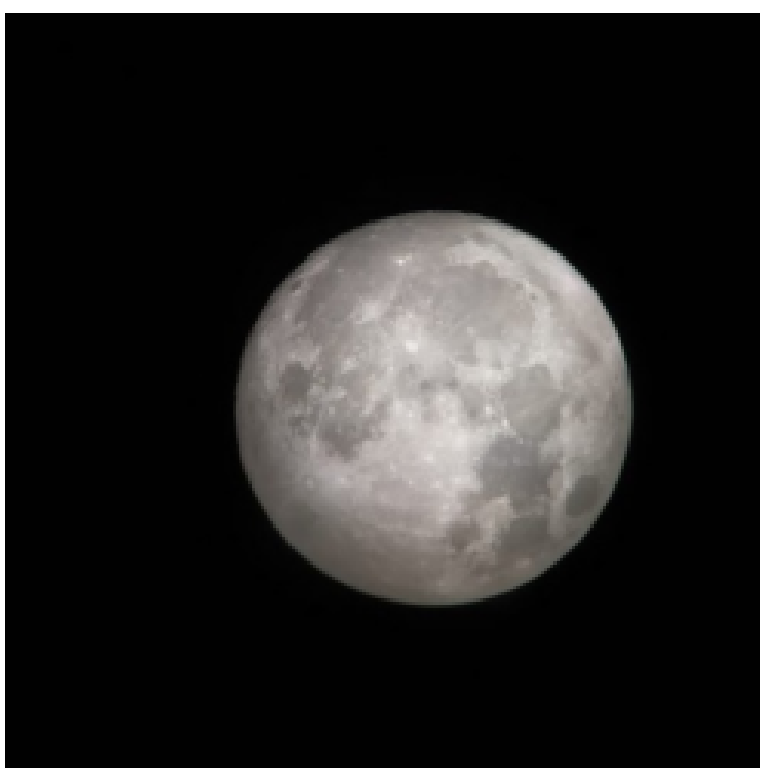

As filas formadas para a observação astronômica foram extensas e o momento de observação seguiu até que não tivessem mais filas formadas ou participantes interessados na visualização. É importante destacar que esta ação beneficiou também os monitores que supervisionaram as atividades e ficaram responsáveis pelo manuseio dos telescópios, uma vez que lhes permitiu integração, interdisciplinaridade curricular e vivência social e cultural.

Além da exposição dos trabalhos e da observação astronômica, foi criado um espaço de interatividade, no qual óculos de realidade virtual foram disponibilizados para que os participantes da Mostra tivessem acesso a um momento de imersão em realidade 3D (Figura 13 (a)). Por meio de um jogo que simula um passeio pela Estação Espacial Internacional (ISS), os alunos puderam conhecer os compartimentos internos da ISS e sentir a sensação de microgravidade. Este espaço de interatividade foi criado ao lado do espaço de observação astronômica e os dois momentos ocorriam simultaneamente. Entre estes dois espaços foram expostos dois banners autoexplicativos que foram preparados com o objetivo de auxiliar os alunos na compreensão do que estava por trás daquele momento de diversão (Figura $13(\mathrm{~b})$ ).

Figura 13: (a) Óculos de realidade virtual. (b) Banners no espaço de interatividade
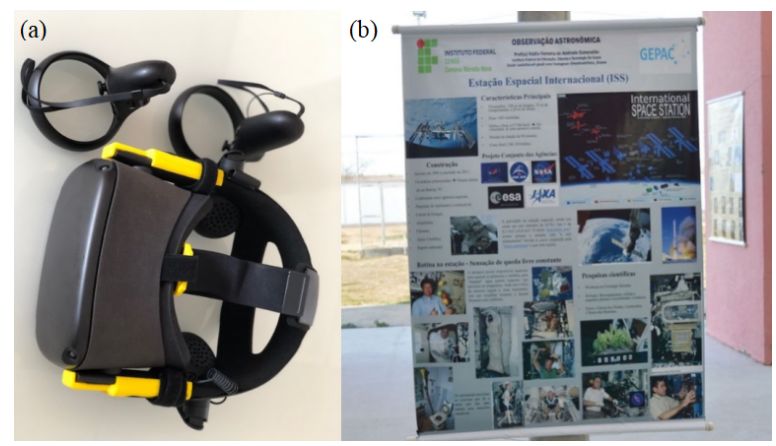

Em um banner havia um breve resumo sobre a história da astronomia, destacando os principais personagens nesse contexto e, no outro, uma exposição por meio de fotos e informações sobre a estrutura da Estação Espacial Internacional (ISS) que é um laboratório espacial completamente concluído.

Foi possível identificar que muitos participantes nunca tinham ouvido falar na ISS e sua descoberta gerou grande admiração e curiosidade entre os participantes. Para coordenar a extensa fila que se formou para utilizar os óculos de realidade virtual, um monitor ficou responsável pela organização da fila e por colocar os óculos em cada participante, auxiliando no uso dos controles enquanto estes passeavam pela ISS. Cada participante tinha a oportunidade de ficar 5 minutos vivenciando este momento de imersão em realidade 3D.

\section{CONSIDERAÇÕES FINAIS}

Tanto pelo relato coletado dos alunos ao longo do evento quanto pelo comportamento desses ao longo das aulas, foi possível identificar o quanto ações como essa são importantes e precisam estar inseridas dentro do processo de ensino e aprendizagem.

A realização da Mostra de Física trouxe benefícios não só para os alunos, mas também para os professores que participaram da ação. Do ponto de vista do aprendizado dos alunos, foi perceptível este fato por meio das associações apresentadas por eles ao longo dos experimentos. Os benefícios decorrentes desta ação alcançaram também a instituição, pois como o evento foi aberto à comunidade externa, a Mostra de Física ganhou um 
RELATO DE UMA EXPERIÊNCIA DIDÁTICA: MOSTRA DE FÍSICA

lugar de destaque como evento de divulgação científica, por meio da observação astronômica e dos experimentos realizados. Assim, a instituição ganhou destaque e reconhecimento diante dos participantes ali presentes.

Vale ressaltar que grande parte dos trabalhos apresentados pelos alunos possuem caráter didático. No entanto, se proporcionado um espaço de criatividade para os alunos, é possível que surjam trabalhos com grande potencial de se transformar em artigos científicos voltados ao ensino de Física. Deste modo, é possível fazer uma análise mais orientada dos trabalhos expostos e avaliar quais podem servir de base para outros estudos futuros.

Diante dos benefícios decorrentes desta ação, podese concluir a importância de eventos como esse inseridos na metodologia dos docentes. Para isso, tanto a gestão quanto os professores precisam trabalhar coordenadamente, para que com o devido apoio, atividades como essas possam ser divulgadas e popularizadas. Ações como essa contribuem positivamente no processo de ensino e aprendizagem dos discentes.

\section{REFERÊNCIAS}

ARAÚJO, M. S. T. d.; ABIB, M. L. V. d. S. Atividades experimentais no ensino de física: diferentes enfoques, diferentes finalidades. Revista Brasileira de ensino de física, SciELO Brasil, v. 25, n. 2, p. 176-194, 2003.

BATISTA, M. C.; FUSINATO, P. A.; BLINI, R. B. Reflexões sobre a importância da experimentação no ensino de física. Acta Scientiarum. Human and Social Sciences, Universidade Estadual de Maringá, v. 31, n. 1, p. 43-49, 2009.

BRASIL. Lei $\mathbf{n}^{0}$ 9.394, de 20 de dezembro de 1996. Estabelece as diretrizes e bases da educação nacional. Brasília, 1996.

Parâmetros Curriculares Nacionais: Ensino Médio. Brasília, 2002.

CONTRERAS, J. Autonomia de Professores. 2. ed. São Paulo: Cortez, 2012.

DEWEY, J. Vida e educação. São Paulo, 1978.

DUARTE, S. Os impactos do modelo tradicional de ensino na transposição didática e no fracasso escolar. Dissertação (Mestrado em Educação) Universidade Fernando Pessoa, Porto, 2018.

FERNANDES, E. F. As Dificuldades de Compreender Física dos Alunos do Ensino Médio das Escolas Públicas de Iguatu - CE. Dissertação
(Licenciatura Plena em Física) — Faculdade de Educação Ciências e Letras, Iguatu, 2016.

FREIRE, P. Pedagogia da autonomia: saberes necessários à prática docente. 1. ed. São Paulo: Paz e Terra, 2003.

FRöBEL, F. W. A. A educação do homem. 1. ed. Passo Fundo: UPF, 2001. Tradução de Maria Helena Câmara Bastos.

GOMES, J. F.; PINTO, E. P.; FILHO, H. D. F. Atividades experimentais como estratégia para o ensino de física: estudo de caso em duas escolas públicas do município de santana - ap. Estação Científica (UNIFAP), v. 7, n. 3, p. 71-81, 2017.

JOYE, C. R. Teorias da aprendizagem da juventude e da idade adulta. 1. ed. Fortaleza: SETEC/IFCE, 2013. 08-82 p.

LEÃO, D. M. M. Paradigmas contemporâneos de educação: escola tradicional e escola construtivista. Cadernos de pesquisa, SciELO Brasil, v. 1, n. 107, p. 187-206, 1999.

MONTESSORI, M. Pedagogia científica: a descoberta da criança. 1. ed. São Paulo: Flamboyant, 1965. Tradução de Aury Azelio Brunetti.

. Para educar o potencial humano. 1. ed. Campinas: Papirus, 2003.

SBF. Relatório: a física e o desenvolvimento nacional. Brasília, 2012.

SILVA, W. V.; DUARTE, M. O ensino de física e atividades experimentais em sala de aula: Algumas considerações. In: Congresso Internacional de Educação e Tecnologias. São Carlos: Anais eletrônicos, 2018. p. 1-10.

TARDIF, M. Saberes docentes e formação profissional. 12. ed. Petrópolis: Vozes, 2011. 